\title{
Ocorrência de Trypanosoma evansi em bovinos de uma propriedade leiteira no município de Videira - SC,Brasil
}

\author{
Occurrence of Trypanosoma evansi in bovines \\ from a dairy farm in the municipality of Videira - SC, Brazil
Aleksandro Schafer da Silva ${ }^{1}$, Camila Belmonte Oliveira ${ }^{1}$, Régis Adriel Zanette ${ }^{1}$, Claudia Dal Molin Soares ${ }^{1}$, Gabriela Coradini ${ }^{1}$, Carlos Henrique Polenz ${ }^{2}$, Janio Morais Santurio ${ }^{3} \&$ Silvia Gonzalez Monteiro ${ }^{3}$

\begin{abstract}
RESUMO
Trypanosoma evansi é um protozoário de distribuição geográfica mundial, detectado na corrente sanguínea de várias espécies de mamíferos. O presente estudo visou relatar um caso de tripanossomose por T. evansi em bovinos de uma propriedade leiteira no município de Videira, Santa Catarina. Nos meses de maio a junho de 2007, dez bovinos adoeceram apresentando sinais clínicos de anorexia, apatia, emagrecimento progressivo, fraqueza, hipertermia $\left(41^{\circ} \mathrm{C}\right)$, mucosas pálidas e hemorragias cutâneas após a morte. Os animais foram tratados para anaplasmose e babesiose, no entanto, quatro não responderam ao tratamento e morreram. Em uma novilha que morreu foi realizado esfregaço sanguíneo periférico. Baseado nos sinais clínicos e nos achados de esfregaço sanguíneo diagnosticou-se o caso como sendo uma infecção mista por T. evansi e Anaplasma marginale, sendo este o primeiro caso deste protozoário em bovino na região sul do país. O desconhecimento da tripanossomose na região sul dificulta o diagnóstico da enfermidade, pois esta apresenta evolução semelhante a outras hemoparasitoses.
\end{abstract}

Descritores: tripanossomose, protozoário, ruminantes, sinais clínicos.

\section{ABSTRACT}

Trypanosome evansi is a protozoan of global geographic spread detected in the blood current of several species of mammals. The present study aimed to report a case of trypanosomosis by T. evansi in bovines from a dairy farm in the municipality of Videira, Santa Catarina. Between May and June of 2007, ten animals were affected and showed clinical signs as anorexy, apathy, progressive loss of weight, weakness, hyperthermia $\left(41^{\circ} \mathrm{C}\right)$, pale mucosae and cutaneous hemorrhage after the death. Animals were treated for anaplasmosis and babesiosis, although four animals did not respond to treatment and died. A blood smear was performed from a dead heifer. The diagnosis of multiple infection by T. evansi and Anaplasma marginale was based on clinical signs and blood smear analysis. This is the first report of this protozoan in the Southern region of Brazil. The diagnosis of the disease is difficult due to the lack of data of the trypanosomosis in Southern Brazil and the similar evolution as other hemoparasitoses.

Key words: trypanosomosis, protozoan, ruminants, clinical signs. 


\section{INTRODUÇÃO}

Tripanossomoses são doenças provocadas por protozoários do gênero Trypanosoma, que têm distribuição cosmopolita e importância econômica na África, Ásia e América Latina [10]. Trypanosoma evansi é um flagelado da seção salivaria, causador da doença conhecida como mal de cadeiras em eqüinos no Pantanal Mato-grossense [17].

No Brasil, T. evansi afeta principalmente equiinos e a prevalência da infecção varia entre regiões [3,8]. Este parasita também pode causar doença clínica em cães, camelos, cabras, capivaras (Hydrochaeris hydrochaeris), bovinos e búfalos [8,18].

Relatos sobre o efeito patogênico de $T$. evansi em cabras, ovelhas e bovinos são contraditórios, sendo que alguns autores consideram que este protozoário causa nestas espécies uma infecção subclínica [12], e outros defendem que T. evansi afeta ruminantes domésticos, causando aborto, infertilidade, baixa de produtividade e morte de animais não tratados [4,13].

T. evansi pode ser transmitido mecanicamente por insetos hematófagos das famílias Tabanidae e Stomoxidae e por morcegos hematófagos [9]. A doença causada por este protozoário é caracterizada por rápida perda de peso, graus variáveis de anemia, febre intermitente, edema dos membros pélvicos e das partes baixas do corpo e fraqueza progressiva [16]. $\mathrm{O}$ presente trabalho teve o objetivo de relatar um caso de tripanossomose por T. evansi em bovinos de uma propriedade leiteira no município de Videira, Santa Catarina.

\section{MATERIAIS E MÉTODOS}

No município de Videira, em uma propriedade de leiteira, nos meses de maio a junho de 2007, verificou-se que dez bovinos adoeceram apresentando sinais clínicos de anorexia, apatia, emagrecimento progressivo, fraqueza, hipertermia $\left(41^{\circ} \mathrm{C}\right)$, mucosas pálidas ou amareladas e hemorragias cutâneas após a morte. Todos os animais doentes foram tratados para anaplasmose e babesiose com oxitetraciclina, dipropionato de imidocarb e aceturato de diminazeno. No entanto, quatro dos ruminantes não responderam ao tratamento e morreram em média 13 dias após iniciar os sinais clínicos e entre 7 a 10 dias após tratamento. Um dos quatro bovinos mortos era uma novilha de 2,5 anos, prenha de oito meses, que havia sido trazida de outra propriedade do município há 30 dias. No dia em que o animal morreu, apresentando todos os sinais descritos anteriormente, foram realizados esfregaços sanguíneos periféricos pelo veterinário que dava assistência ao produtor. Os mesmos foram encaminhados ao laboratório de Parasitologia Veterinária e corados com Panotico rápido ${ }^{\circledR}$, para posterior observação em microscópico óptico em aumento de 1000 vezes.

\section{RESULTADOS}

Os parasitos encontrados no bovino foram identificados morfologicamente e biometricamente como Trypanosoma (Trypanozoon) evansi (Steel, 1885) Balbiani, 1888 conforme a literatura [15,17] (Figura 1). Os quatro flagelados encontrados neste estudo não apresentavam cinetoplasto, característica típica de cepas brasileiras.

\section{DISCUSSÃO}

A evolução da tripamossomose e os sinais clínicos apresentados pelos animais da propriedade são compatíveis com outros trabalhos [13,16], que ocorreram em um curto intervalo de tempo caracterizando um surto. Neste estudo, o diagnóstico foi baseado nos sinais clínicos e nos achados de esfregaço sanguíneo que mostraram a presença de quatro formas tripomastigotas de $T$. evansi, além de várias hemácias parasitadas por Anaplasma marginale, na lâmina confeccionada. Alguns autores reportam que a presença de outros agentes, tais como Babesia sp. e Anaplasma sp., podem mascaram o diagnóstico da doença causada por Trypanosoma sp. [19].

Este trabalho visa relatar a primeira ocorrência de infecção por T. evansi em bovinos da região sul do país, embora o esse protozoário já tenha sido descrito no Rio Grande do Sul parasitando cães e eqüino [1,16]. No Brasil, o T. vivax é a espécie de maior incidência em ruminantes, esta afirmação é confirmada em um estudo realizado no Pantanal, onde se verificou que a prevalência de $T$. evansi nos bovídeos é inferior a de $T$. vivax, isto é, $8,10 \%$ para $T$. evansi e de 44,70\% para T. vivax através do método de PCR [2]. Esta diferença, segundo os autores, pode estar relacionada à baixa patogênicidade do T. evansi para ruminantes, o que acarreta uma leve parasitemia, dificultando a transmissão entre os bovinos [2].

Conforme a literatura, o T. evansi pode acometer várias espécies de mamíferos, entretanto, o parasitismo em bovinos não é comumente observado no país, sendo este flagelado detectado, em lâmina, 


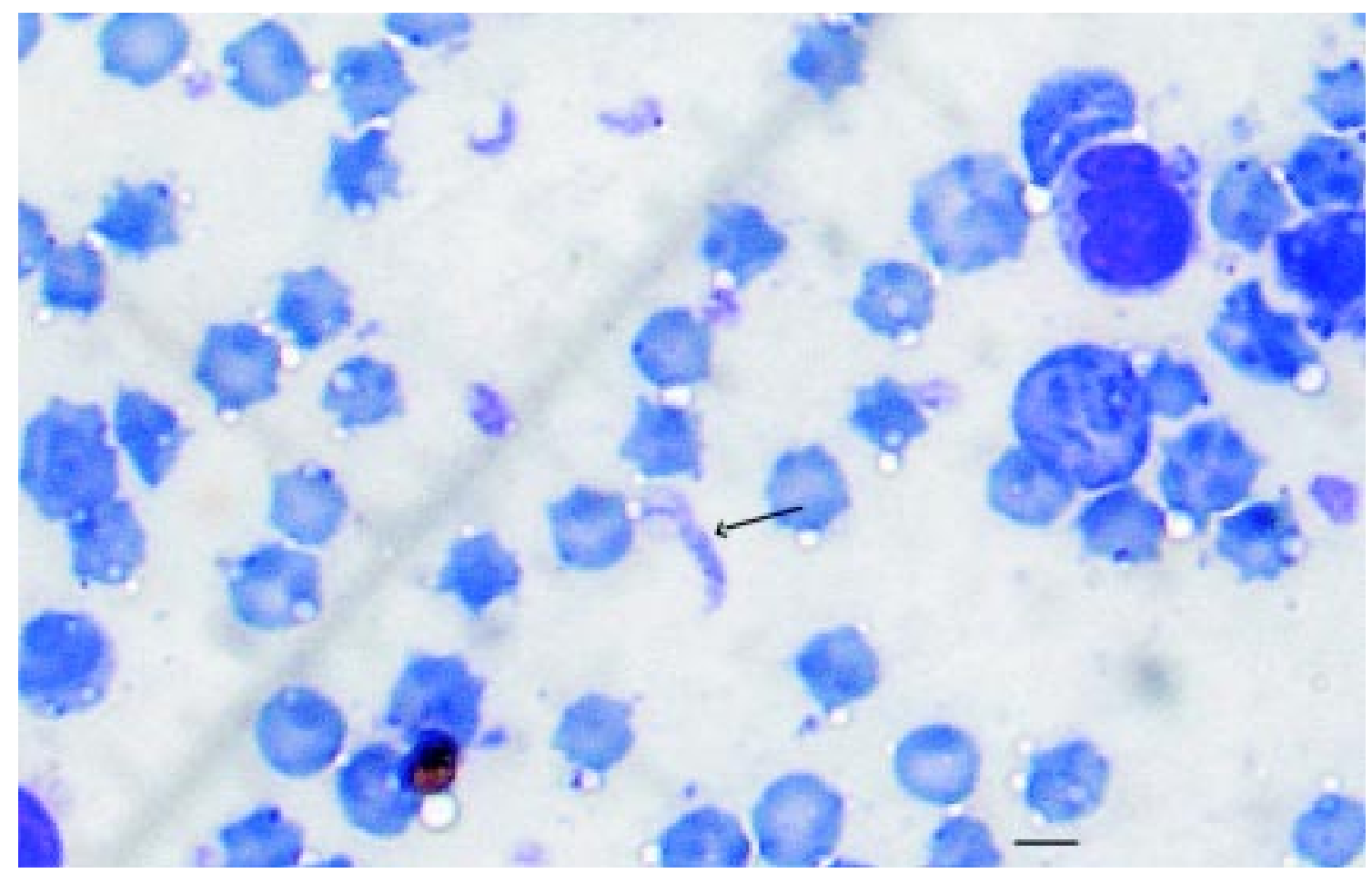

Figura 1. Forma tripomastigota de Trypanosoma evansi identificado em esfregaço sangüíneo de bovinos oriun-

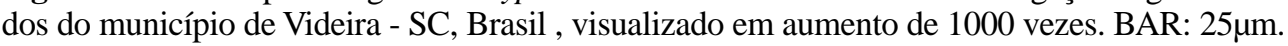

apenas em bovinos do pantanal mato-grossense. Há maioria dos casos considerados positivos para o parasito, não identificaram a forma tripomastigota, mas sim soroprevalência [6,8]. Infecções naturais por este protozoário, também são reportadas em cabras e búfalos em áreas de clima tropical [7,11].

Pesquisadores avaliaram bezerros e cabras infectadas experimentalmente por T. evansi [12,13], verificando um aumento de temperatura corporal (febre) e detecção do protozoário na circulação após alguns dias da inoculação, achados estes, observados neste estudo. No entanto, os sinais clínicos verificados neste caso são frequentemente relatados em cavalos e cães $[1,16]$.

Na maioria dos casos de surtos por T. evansi em eqüinos, estes vêm precedidos de surtos em capivaras, considerados um dos principais reservatórios $[8,16,17]$. No ambiente em que os animais deste estudo se encontravam não se registrou presença deste roedor, no entanto, verificou-se um grande número de gambás (Didelphis sp.), um marsupial que pode ser parasitado naturalmente por Trypanosoma cruzi e Trypanosoma rangeli conforme relatos [5,14]. Segundo alguns autores, pequenos marsupiais (Monodelphis sp.) também podem ser hospedeiro de T. evansi [8] e baseado nessas informações pode-se suspeitar do gambá como possível reservatório para o parasito na propriedade. $\mathrm{O}$ grande número de insetos, mutucas e moscas, podem atuar como vetores deste agente etiológico, acarretando em um surto de tripanossomose [9].

\section{CONCLUSÃO}

Com base nos resultados, conclui-se que o $T$. evansi está cada vez mais presente na região sul, tornando-se um problema para os pecuaristas, e o desconhecimento da tripanossomose na região ainda dificulta o diagnóstico, pois esta apresenta evolução semelhante a outras hemoparasitoses.

\section{REFERÊNCIAS}

1 Colpo C.B., Colpo E.T.B., Stainki D.R. \& Monteiro S.G. 2005. Infecção natural por Trypanosoma evansi em cão no Rio Grande do Sul. Ciência Rural. 35: 717-719.

2 Davila A.M.R., Herrera H.M., Schlebinger T., Souza S.S. \& Traub-Cseko Y.M. 2003. Using PCR for unravelling the cryptic epizootiology of livestock trypanosomosis in the Pantanal, Brazil. Veterinary Parasitology. 117: 1-13. 
3 DávilaA.M.R. \& Silva R.A.M.S. 2000. Animal trypanosomiasis in South America. Current status, partnership, and information technology. Annals of the New York Academy of Sciences. 916: 199-212.

4 Desquesnes M., Bengaly Z., Millogo L., Meme Y. \& Sakande H. 2001. The analysis of the cross reactions occurring in antibody-Elisa for the detection of trypanosomes can improve identification of the parasite species involved. Annals of Tropical Medicine and Parasitology. 95: 141-153.

5 Fernandes A.J., Luz Z.M.P., Vitor R.W.A., Diotaiuti L. \& Chiari E. 1994. Possibilidade de autocura em gambá (Didelphis albiventris) naturalmente infectado pelo Trypanosoma cruzi. Revista do Instituto de Medicina Tropical de São Paulo. 36: 471-473.

6 Franke C.R., Greiner M. \& Mehlitz D. 1994. Investigations on naturally occurring Trypanosoma evansi infections in horses, cattle, dogs and capybaras (Hydrochaeris hydrochaeris) in Pantanal de Pocone (Mato Grosso, Brazil). Acta Tropica. 58: $159-169$.

7 Guitierrez C., Corbera J.A., Morales M. \& Büscher P. 2006. Trypanosomosis in goats: Current status. Annals of the New York Academy of Sciences. 1081: 300-310.

8 Herrera H.M., Rademarker V., Abreu U.G.P., Dandrea P.S. \& Jansen A.M. 2004. Enzootiology of Trypanosoma evansi in Pantanal, Brazil. Veterinary Parasitology. 125: 263-275.

9 Hoare C.A. 1972. The Trypanosomes of mammals: a zoological monograph. Blackwell: Oxford, 749p.

10 Lun Z.R. \& Desser S.S. 1995. Is the broad range of hosts and geographical distribuition of Trypanosoma evansi attributable to the loss of maxicircle kinetoplast DNA? Parasitology Today. 11: 131-133.

11 Lun Z.R., Min Z.P., Huang D., Liang J.X., Yang X.F. \& Huang YT. 1991. Cymelarsan in the treatment of buffaloes naturally infected with Trypanosoma evansi in South China. Acta Tropica. 49: 233-236.

12 Ngeranwa J., Gathumbi P.K., Mutiga E.R. \& Agumbah G.J. 1993. Pathogenesis of Trypanosoma (brucei) evansi in small east African goats. Research in Veterinary Science. 54: 283-289.

13 Payne R., Sukanto I.P., Partoutomo S. \& Polytedi F. 1992. Experimental infection of Friesian isolate of Trypanosoma evansi. Tropical Medicine and Parasitology. 43: 115-117.

14 Ramirez L.E., Machado M.I., Maywald P.G., Matos A., Chiari E. \& Silva E.L. 1998. Primeira evidência de Trypanosoma rangeli no sudeste do Brasil, região endêmica para doença de Chagas. Revista da Sociedade Brasileira de Medicina Tropical. 31: 99-102.

15 Ramirez L.E., Silva R.A.M.S., Trajano V. \& Jansen A.M. 1997. Measurements of Trypanosoma evansi isolates from wild and domestic animals of the pantanal. Memórias do Instituto Oswaldo Cruz. 92: 483-484.

16 Rodrigues A., Fighera R.A., Souza T.M., Schild A.L., Soares M.P., Milano J. \& Barros C.S.L. 2005. Outbreaks of Trypanosomiasis in horses by Trypanosoma evansi in the state of Rio Grande do Sul, Brazil: epidemiological, clinical, hematological, and pathological aspects. Pesquisa Veterinária Brasileira. 25: 239-249.

17 Silva R.A.M.S., Seidl A., Ramirez L. \& Dávila A.M.R. 2002. Trypanosoma evansi e Trypanosoma vivax - Biologia, Diagnóstico e Controle. Manual EMBRAPA Online. Disponível em: http://www.cpap.embrapa.br/publicacoes/online/ Livro015. Acessado em 01/2005.

18 Silva R.A.M.S., Herrera M.M., Domingos L.B.S. 1995. Pathogenesis of Trypanosoma evansi infection in dogs and horses: hematological and clinical aspects. Ciência Rural. 25: 233-238.

19 Wells E.A. 1984. Animal trypanosomiasis in South America. Preventive Veterinary Medicine. 2: 31-41. 